\title{
Glucose-induced loss of glycosyl-phosphatidylinositol-anchored membrane regulators of complement activation (CD59, CD55) by in vitro cultured human umbilical vein endothelial cells
}

\author{
A. Accardo-Palumbo ${ }^{1}$, G. Triolo ${ }^{1}$, G.Colonna-Romano ${ }^{3}$, M.Potestio ${ }^{3}$, M. Carbone ${ }^{1}$, A.Ferrante ${ }^{1}$, E. Giardina $^{1}$, \\ G. Caimi' ${ }^{2}$ G.Triolo ${ }^{1}$ \\ ${ }^{1}$ Department of Internal Medicine, Section of Clinical Immunology, Rheumatology and Allergy, University of Palermo, \\ Palermo, Italy \\ ${ }^{2}$ Department of Internal Medicine, Section of Clinical Methodology, University of Palermo, Palermo, Italy \\ ${ }^{3}$ Department of Pathology, University of Palermo, Palermo, Italy
}

\begin{abstract}
Aims/hypothesis. This study examines whether increased glucose concentrations are responsible for a decreased expression of membrane regulators of complement activation molecules. The effect of high glucose in determining an increase in membrane attack complex deposition on endothelial cells was also investigated.

Methods. Endothelial cells were isolated from umbilical cord tissue, cultured in the presence of increased concentrations of glucose, and the expression of CD46, CD55, and CD59 was detected by ELISA (enzyme-linked immunosorbent assay) and by flow cytometry. Glucose-treated endothelial cells were also incubated with antiendothelial cell antibodies and fresh complement to assess the amount of membrane attack complex formation.

Results. High concentrations of glucose decreased the expression of CD59 and CD55 by endothelial cells in a time-dependent and glucose concentration-dependent manner without affecting CD46 expression. High concentrations of soluble CD59 were found in
\end{abstract}

the supernatants of cells treated with high glucose. The decrease in CD59 expression induced by high glucose concentrations was reversed by coincubation of cells with a calcium channel blocking agent (Verapamil). All of these effects were not reproduced by osmotic control media. Cells treated with concentrations of high glucose were more susceptible to complement activation and membrane attack complex formation after exposure to antiendothelial cell antibodies.

Conclusion/Interpretation. We speculate that hyperglycaemia could directly contribute to a loss of CD59 and CD55 molecules through a calcium-dependent phosphoinositol-specific phospholipase $\mathrm{C}$ activation and subsequent regulation of cell wall expression of GPI-anchored proteins. This phenomenon could facilitate the activation of a complement pathway and could play a part in the aetiology of endothelial dysfunction in diabetes. [Diabetologia (2000) 43: 1039-1047]

Keywords CD59, CD55, CD46, endothelial cells, glucose, diabetes mellitus, vascular complications, MAC
Received: 31 January 2000; Accepted: 8 May 2000

Corresponding author: Professor G. Triolo, Cattedra di Allergologia e Immunologia Clinica, Istituto di Clinica Medica, Policlinico Universitario, Piazza delle Cliniche 2, 90127 Palermo, Italy

Abbreviations: AECA, anti-endothelial cell antibodies; CD46, membrane CD-factor protein; CD55, decay accelerating factor DAF; CD59, membrane inhibitor of reactive lyisis MIRL; GPI, glycosyl-phosphatidylinositol; MAC, membrane attack complex; mRCA, membrane regulators of complement activation; PI-PLC, phosphoinositol-specific phospholipase; PKC, protein kinase $\mathrm{C}$; PLC, phospholipase $\mathrm{C}$
Several lines of evidence suggest that one of the primary events in the course of diabetic vascular pathology is an alteration affecting the endothelial cell function, including abnormalities of vessel tone and permeability, coagulation, blood flow, basement membrane synthesis and turnover and the appearance of specific adhesive glycoproteins promoting the binding and migration of mononuclear cells [1,2]. Hyperglycaemia and immunological factors could trigger the development of these abnormalities [3, 4].

Many findings show that activation of a complement system occurs in diabetic patients. Complement 
molecules have been found to be deposited in the blood vessel wall, in glomerular vessels and in the mesangial area of diabetic kidneys [5-7]. Increased concentrations of soluble noncytolytic C5b-9 were also found in the plasma of diabetic patients together with an increased concentration of von Willebrand Factor, a marker of endothelial dysfunction [8].

Complement-mediated destruction of autologous cells is regulated by many factors: decay-accelerating factor (DAF, CD55), membrane co-factor protein (MCP, CD46), C3b receptor, sialic acid and CD59 (membrane inhibitor of reactive lysis, MIRL) [9]. The molecules CD55 and CD59 belong to a family of membrane proteins that are attached to the outer leaflet of the cell membrane through a glycosyl-phosphatidylinositol (GPI) moiety $[10,11]$.

In this study we report that in vitro treatment of human umbilical vein endothelial cells with a high glucose concentration causes a loss of the expression of GPI-anchored CD55 and CD59 without affecting the expression of the transmembrane molecule CD46. We also show that glucose-treated endothelial cells are prone to $\mathrm{C} 5 \mathrm{~b}-9$ deposition after reaction with antiendothelial cell antibodies, purified from the plasma of diabetic patients and fresh human complement.

\section{Design and methods}

Reagents and monoclonal antibodies. Collagenase (class I) was purchased from Boehringer Mannheim (Mannheim, Germany), Fetal Calf Serum (FCS) from Sebam (Berlin, Germany), endothelial cell growth factor from SERVA-Boehringer Ingelheim (Heidelberg, Germany), and heparin from Novo Nordisk (Bagsvaerd, Denmark). The L-glutamine and antibiotics were purchased from Irvine Scientific (Santa Ana, Calif., USA). The D-glucose, L-glucose and other chemicals were of reagent grade and were obtained from commercial sources. Verapamil was kindly provided by the pharmacy of the Internal Medicine Division of the University of Palermo. Monoclonal antibody (MAb) directed against CD59 and the biotin conjugate were obtained from ICN Biomedicals (Irvine, Calif., USA) and Pharmingen (Los Angeles, Calif., USA). Monoclonal antibodies (MAb) directed against CD55 and CD46 were also obtained from Pharmingen. The $\mathrm{F}(\mathrm{ab} 2)$ goat anti-mouse IgGFITC and normal mouse IgG were purchased from Dako (Copenhagen, Denmark) and the alkaline-phosphatase antimouse IgG from Sigma (St Louis, Mo., USA). The control medium comprised the standard culture medium (see methods) and contained $5 \mathrm{mmol} / \mathrm{l} \mathrm{D}$-glucose. The high-glucose medium was identical to the control medium but was supplemented with D-glucose to increase its concentration to $30 \mathrm{mmol} / \mathrm{l}$. The L-glucose osmotic control medium was identical to the control medium but was supplemented with L-glucose, a cell-permeable but poorly metabolised glucose isomer, (D-glucose $5 \mathrm{mmol} / \mathrm{l}+25 \mathrm{mmol} / \mathrm{l} \mathrm{L}$-glucose) which served as osmotic control for the high-glucose medium but also, because so poorly metabolised, served as metabolic control.

Cell isolation and culture. Endothelial cells were isolated from umbilical cord tissue obtained from healthy pregnant women with blood group 0 by collagenase digestion according to the method of Jaffe [12]. Cells were grown in Medium 199 containing $20 \% \mathrm{FCS}$ and supplemented with $2 \mathrm{mmol} / \mathrm{l}$ glutamine, 100 $\mathrm{U} / \mathrm{ml}$ penicillin, $100 \mu \mathrm{g} / \mathrm{ml}$ streptomycin, $50 \mu \mathrm{g} / \mathrm{ml}$ endothelial growth factor and $20 \mathrm{U} / \mathrm{ml}$ heparin. Morphology was confirmed by contrast-light phase microscopy and characterised by immunofluorescent staining with antifactor VIII antigen antibodies conjugated with fluorescein isothiocyanate conjugate (FITC). Cells at first passage were removed from the flask using $0.25 \%$ trypsin EDTA, washed and transferred to wells of 96-well microtitre plates and allowed to grow in high glucose medium or in control medium. Controls for osmolarity were cells grown in L-glucose osmotic control medium. Endothelial cells were cultured for 1-10 days with feeding at 2-day intervals with the specific medium and then washed twice in PBS and fixed with $1 \%$ glutaraldehyde for $30 \mathrm{~min}$ at room temperature for the measurement of CD59, CD55 and CD46 expression by ELISA. For flow cytometric studies, endothelial cells at first passage were recultured in a $25 \mathrm{~cm}^{2}$ flask with the standard medium until confluence was achieved (usually 24-72 h) and in the presence of control medium, high glucose medium or L-glucose osmotic control medium for the following 1-3 days.

ELISA for determination of CD59, CD55 and CD46 expression on endothelial cells. Fixed endothelial cell monolayers were incubated with PBS containing $10 \%$ FCS to reduce nonspecific binding, and reacted for $1 \mathrm{~h}$ with mouse MAb against CD59, CD55, and CD46. Bound antibodies were detected by antimouse IgG conjugated with alkaline phosphatase. Unbound antibodies were removed by washing and $1 \mathrm{~mol} / \mathrm{l}$ diethanolamine $\mathrm{HCl}$ buffer $\mathrm{pH} 9.8$ containing $1 \mathrm{mg} / \mathrm{ml} p$-nitrophenylphosphate di-sodium was added. Absorbance was read at 405 $\mathrm{nm}$ in an automated spectrophotometer. Controls included the omission of the primary antibody (blank) and incubation with medium alone. Results were expressed as optical density units after subtraction of blank values.

Measurement of CD59, CD55 and CD46 expression on endothelial cells by flow cytometric analysis. Cells that had been exposed to the different medium were harvested in unicellular suspension by treatment with trypsin EDTA, washed in PBS and resuspended at $1 \times 10^{6} \mathrm{cell} / \mathrm{ml}$. A $300 \mu \mathrm{l}$ cell suspension was reacted with the first (unconjugated) antibody (antiCD59 $10 \mu \mathrm{g} / \mathrm{ml}$; anti-CD55 $50 \mu \mathrm{g} / \mathrm{ml}$; anti-CD46 $50 \mu \mathrm{g} / \mathrm{ml}$ ) on ice for $20 \mathrm{~min}$, washed three times with PBS and incubated for an additional $20 \mathrm{~min}$ with the second antibody (FITC-conjugated $\mathrm{F}(\mathrm{ab} 2)$ goat anti-mouse $\mathrm{IgG}$ ). Isotype control IgG was used as a negative control. The stained cells were washed twice in PBS and then analysed by FACScan flow cytometer (Becton Dickinson, Mountain View, Calif., USA). All measurements were made with the same instrument setting and at least $10^{4}$ cells were analysed using Lysis II software (Becton Dickinson). Results were expressed mean fluorescence intensity (MFI).

Measurement of soluble CD59 in the supernatants of endothelial cell cultures. Supernatants of cells cultured in the various conditions were collected, centrifuged at $1500 \mathrm{rpm}$ for $15 \mathrm{~min}$ to remove any detached cells and debris and stored immediately at $-30^{\circ}$ for CD59 measurement. The 96-well microtitre plates adsorbed with anti-CD59 monoclonal antibody (clone 2/24 indentical to YTH 53.1 antibody, mouse IgG1 isotype) were obtained from ICN Biomedicals, Irvine, Calif., USA. Plates were prepared by incubating wells with $1 \mu \mathrm{g} / \mathrm{ml}$ of the antibody in carbonate buffer for $48 \mathrm{~h}$ at $4{ }^{\circ} \mathrm{C}$. Wells were then reacted with undiluted supernatants for $2 \mathrm{~h}$ at $37^{\circ} \mathrm{C}$, washed with PBS-Tween and incubated consecutively with 1:500 dilu- 
tion of biotin-labelled anti-CD59 monoclonal antibody (clone p282-H19, mouse IgG2a isotype) obtained from Pharmingen, Los Angeles, Calif., USA and the avidin-HRP conjugate. After the addition of the specific substrate, the color reaction was read at $492 \mathrm{~nm}$ in an automated spectrophotometer. Results were expressed as optical density units after the subtraction of blank values.

Inhibition of the high-glucose effect on endothelial cells by calcium channel blocking. To determine the functional role of calcium channel blocking in CD59 and CD55 endothelial cell expression after incubation with high concentrations of glucose, experiments were carried out in which Verapamil at $40 \mu \mathrm{mol} / 1$ concentration was added to each culture and the molecules measured, as described, by flow cytometric analysis.

Preparation of human Ig. To purify human immunoglobulin (Ig), sera pooled from five diabetic patients with known high positivity for antiendothelial cell antibodies (AECA), were processed by ammonium sulphate precipitation and protein A-Sepharose chromatography. Total proteins were determined using the bicinchrominic method (Pierce, Rockford, Ill., USA) and adjusted to $200 \mu \mathrm{g} / \mathrm{ml}$. Some purified Ig were depleted of AECA by repetitive incubation with endothelial cell cultures. Depletion of antiendothelial cell activity to undetectable concentrations was confirmed by ELISA [4].

C5b-9 formation on endothelial cells. Wells containing endothelial cell monolayers treated with high concentrations of glucose were incubated for $1 \mathrm{~h}$ with $20 \mu \mathrm{g}$ of AECA positive or AECA negative Ig and then with $25 \mu \mathrm{l}$ of fresh human serum (as a donor of homologous complement) for another hour at $37^{\circ} \mathrm{C}$. Endothelial cells treated with standard medium were used as control. Analyses were carried out using the following: a) endothelial cells without complement source and anti C5b9; b) endothelial cells + antibody and no complement; c) endothelial cells + glucose + antibody and complement, d) endothelial cells + glucose + no antibody + no complement. Wells were repeatedly washed, fixed with glutaraldheyde and C5b-9 detected by monoclonal anti C5b-9 antibody (Dako, Copenhagen, Denmark) followed by an alkaline phosphataseconjugated anti-mouse antibody. Results were expressed as optical density units. Supernatants from all experiments were also collected and analysed for lactic dehydrogenase enzyme activity by commercial standard methods.

Statistical analysis. All experiments were performed on at least six separate occasions unless otherwise indicated. Results are expressed as the means \pm SD. Differences in mRCA molecule expression were compared by ANOVA followed by a post hoc test (Bonferroni Test) and by Student's $t$ test for paired and unpaired data. A $p$ value less than 0.05 was considered significant.

\section{Results}

Effect of elevated glucose concentrations on CD59, CD55 and CD46 expression by human endothelial cells. Endothelial cell monolayers were exposed to control media or high glucose medium containing $30 \mathrm{mmol} / \mathrm{l} \mathrm{D}$-glucose concentration for 3 days and CD59, CD55 and CD46 expression was determined by ELISA. As shown in Figure 1, CD59 and CD55 expression by human endothelial cells exposed to D-glu-

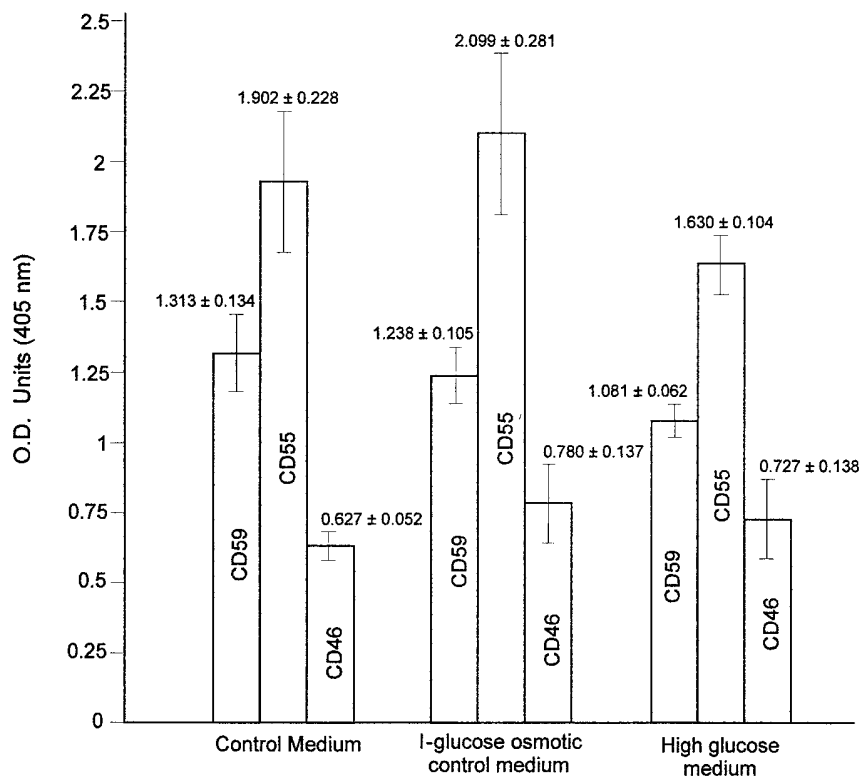

Fig.1. Expression of CD59, CD55 and CD46 by human endothelial cells after 3-day exposure to control medium, L-glucose osmotic control medium and high $(30 \mathrm{mmol} / \mathrm{l}) \mathrm{D}$-glucose medium as determined by ELISA. Results are expressed as optical density (OD) units \pm standard deviation. The expression of CD59 and CD55 cells treated with high glucose medium was decreased $(p<0.001)$ when compared with the expression on cells cultured with control medium or L-glucose osmotic control medium or both. No effect was observed on CD46 expression. Expression of CD46 and CD55 on cells treated with Lglucose was increased $(p=0.01)$ when compared with the expression of cells cultured with control medium.

cose was significantly decreased (CD59, $1.081 \pm$ 0.062 ; CD55, $1.630 \pm 0.104 ; n=20)$ when compared with the expression by cells incubated with control medium (CD59, $1.313 \pm 0.134, p<0.001$; CD55, $1.902 \pm 0.228, p<0.001 ; n=20)$. Exposure to D-glucose had no effect on CD46 expression (Fig. 1). To determine whether the loss of expression of CD59 and CD55 was secondary to changes in osmolarity caused by high glucose concentrations, cells were grown for the same period in L-glucose. We did not observe a loss of mRCA molecules. (Fig.1). Indeed, the expression of all mRCA molecules was slightly increased in endothelial cells exposed to L-glucose the difference being significant for CD46 and CD55 expression $(p<0.01)$, (Fig. 1). Flow cytometric studies were done to determine also whether the cell number/confluence in the monolayer might influence the ELISA. More remarkable results were obtained utilising a flow cytometric analysis to show the effect of high glucose concentrations on CD59, CD55 and CD46 expression by endothelial cells. Exposure to Dglucose was followed by a consistent decrease in CD59 $(99 \pm 25.5, n=6)$ and CD55 $(43.6 \pm 19, n=6)$ expression $[p<0.001$ vs control medium $(219 \pm 19.8$ and $196 \pm 41$ respectively, $n=6$ )], (Fig.2). No changes were observed after L-glucose incubation (Fig. 2) 


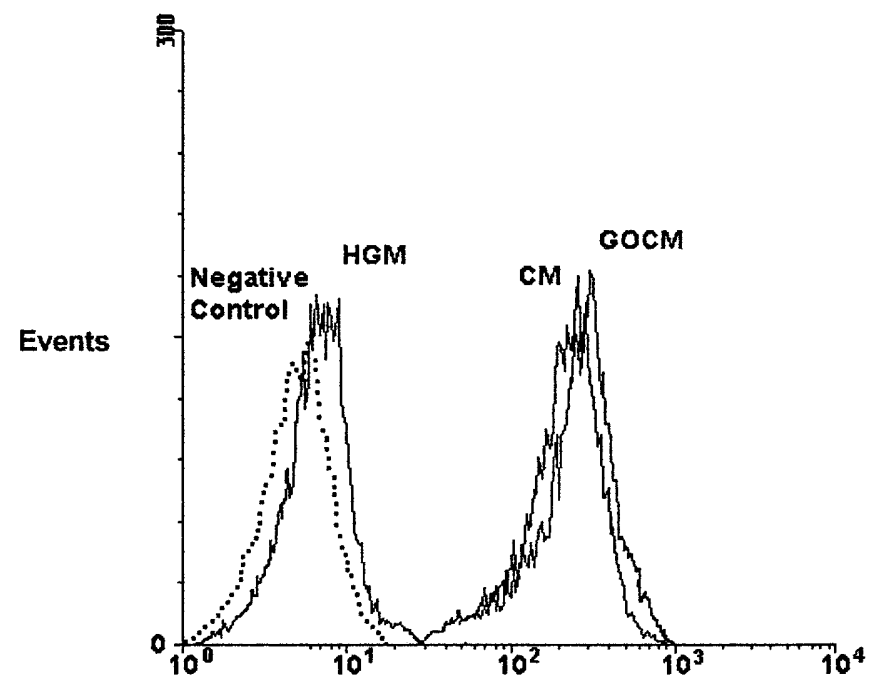

a
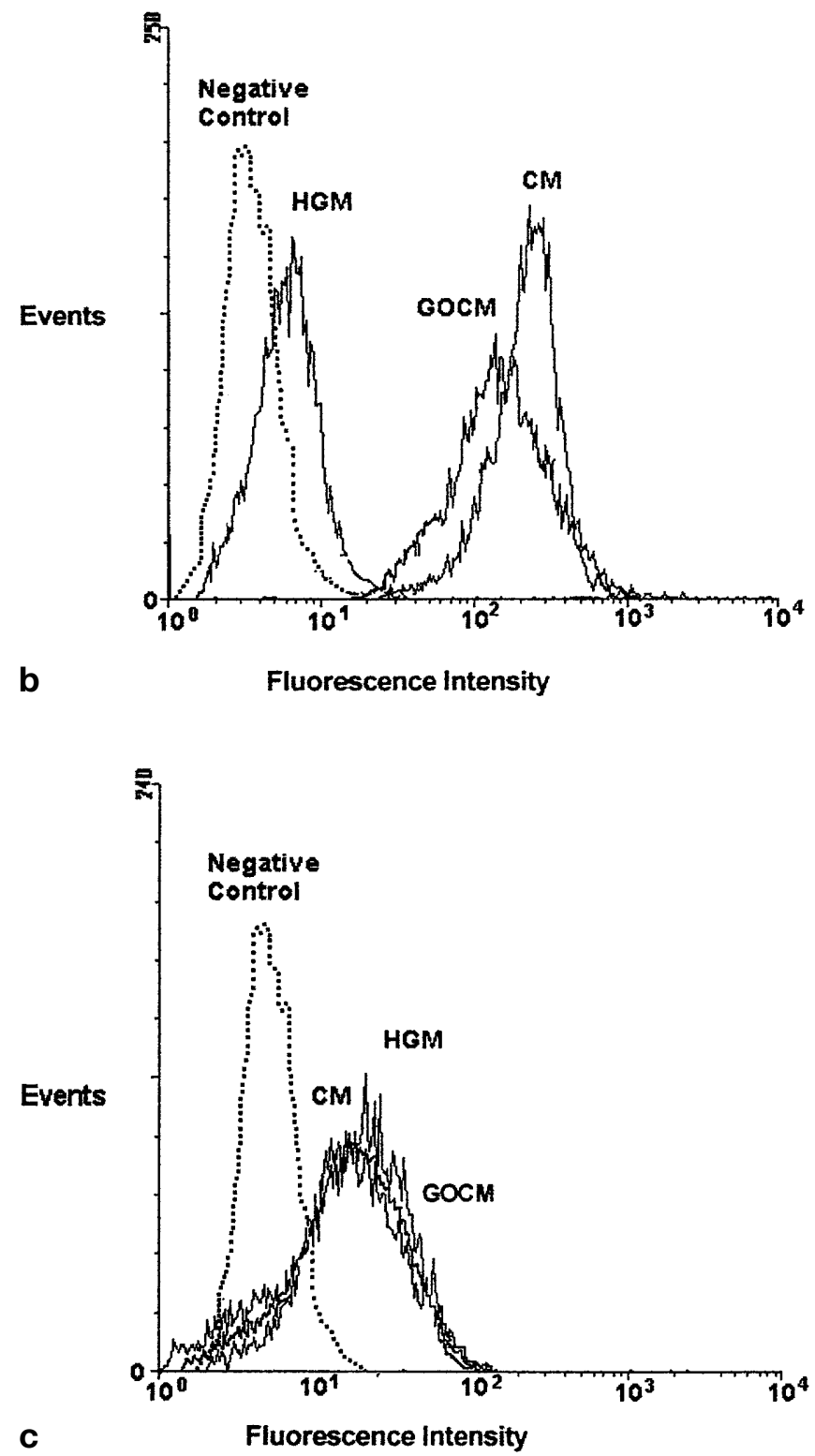

or in the CD46 expression under various culture conditions (control medium, $44.6 \pm 16$; D-glucose, $44 \pm 17.4$; L-glucose, $43 \pm 13.3$; $n=6$ ), (Fig. 2 ). In additional experiments the course of time over which the glucose-dependent decrease of CD59 and CD55 expression occurred was examined by ELISA, by exposing cells to control media or high glucose medium containing $30 \mathrm{mmol} / \mathrm{l}$ glucose for up to 10 days. The decrease of CD59 expression induced by D-glucose was present after 1 day of exposure and was observed to be more consistent after 6-10 days (Table 1 ). Similar results were obtained for CD55 expression (Table 2). On day 1 a slight increase of CD55 and CD59 was observed in the cells treated with L-glucose. Cells were also exposed to various $\mathrm{D}$-glucose concentrations of $20-40 \mathrm{mmol} / \mathrm{l}$ for 6 days and CD59 expression was measured by ELISA. As shown in Table 3, CD59 expression by endothelial cells progressively decreased, increasing the D-glucose concentration. No significant changes increasing the concentration of L-glucose osmotic control medium were observed (Table 3).

Concentrations of soluble CD59 in supernatants of endothelial cell cultures. In contrast with decreased CD59 expression on cells, significantly increased concentrations of the soluble form of CD59 were found in the supernatants of cells cultured for 6 days in high $(30 \mathrm{mmol} / \mathrm{l})$ D-glucose ambient $(0.571 \pm 0.043$, $n=8)$ ) when compared with those obtained from cells cultured in $5 \mathrm{mmol} / \mathrm{l}$ (control medium) D-glucose $(0.340 \pm 0.060, n=8, p<0.001)$ or L-glucose osmotic control medium $(0.387 \pm 0.108, n=8, \quad p<0.001)$, (Fig. 3).

Effect of Verapamil treatment on CD59 endothelial cell expression. If the glucose-mediated release in calcium-dependent PLC activity is due in part to calcium influx, a calcium channel blocker should totally or partially inhibit this effect. To examine this issue we incubated endothelial cells for 3 days in media containing $5 \mathrm{mmol} / \mathrm{l}$ D-glucose or $5 \mathrm{mmol} / \mathrm{l}$-glucose

Fig. 2. Effect of culturing human endothelial cell with control medium (CM), L-glucose osmotic control medium (GOCM) and high (30 mmol/l) glucose medium (HGM) on mRCA expression. Following 3-day culture, human endothelial cells were then incubated with predetermined optimal binding concentrations of $\mathbf{A}$. anti-CD59 monoclonal antibody (MAb) or murine $\mathrm{IgG}, \mathbf{B}$. anti-CD55 or murine $\mathrm{IgG}, \mathbf{C}$. anti-CD46 or murine IgG. Surface-bound antibody was detected using fluorescein isothiocyanate-conjugated goat $\mathrm{F}(\mathrm{ab}) 2$ anti-mouse $\mathrm{Ig}$, and fluorescence intensity was measured by flow cytometry. Data shown are from a representative experiment, with fluorescence intensity along the $\mathrm{x}$ axis and number of events along the y axis. Similar results were observed in six repeat experiments. 
Table 1. Effect of high $(30 \mathrm{mmol} / \mathrm{l})$ glucose medium on CD59 expression by endothelial cells cultured for 1-10 days. High glucose concentrations decreased the expression of CD59 in a time-dependent manner. A. Statistically different $(p<0.001)$ from CD59 expression by endothelial cells exposed to high glucose medium for 1 day. B. Statistically different $(p<0.005)$

from CD59 expression by endothelial cells exposed to high glucose medium for 3 days. C. Statistically different $(p<0.001)$ from CD59 expression by endothelial cells exposed to high glucose medium for 6 days. D. Statistically different $(p<0.01)$ from CD59 expression by endothelial cells exposed to control medium

\begin{tabular}{lclllll}
\hline Incubation time & $n$ of experiments & $\begin{array}{l}\text { Control medium } \\
\text { OD } \pm \text { SD }\end{array}$ & $p$ & $\begin{array}{l}\text { High-glucose medium } \\
\text { OD } \pm \text { SD }\end{array}$ & $p$ & $\begin{array}{l}\text { L-glucose osmotic } \\
\text { control medium } \\
\text { OD } \pm \text { SD }\end{array}$ \\
\hline 1 day & 6 & $1.485 \pm 0.118$ & NS & $1.343 \pm 0.073$ & $<0.001$ & $1.704 \pm 0.151$ \\
3 days & 20 & $1.313 \pm 0.134$ & $<0.001$ & $1.081 \pm 0.062^{\mathrm{a}}$ & $<0.001$ & $1.238 \pm 0.105$ \\
6 days & 18 & $1.342 \pm 0.096$ & $<0.001$ & $1.020 \pm 0.049^{\mathrm{b}}$ & $<0.001$ & $1.281 \pm 0.077$ \\
10 days & 16 & $1.280 \pm 0.108$ & $<0.001$ & $0.923 \pm 0.121^{\mathrm{c}}$ & $<0.001$ & $1.250 \pm 0.107$ \\
\hline
\end{tabular}

Table 2. Effect of high (30 mmol/l) glucose medium on CD55 expression by endothelial cells cultured for 1-10 days. High glucose concentrations decreased the expression of CD55 in a time-dependent manner. A. Statistically different $(p<0.001)$ from CD55 expression by endothelial cells exposed to high glucose medium for 1 day. B. Expression by endothelial cells ( $p$,

\begin{tabular}{|c|c|c|c|c|c|c|}
\hline Incubation time & $n$ of experiments & $\begin{array}{l}\text { Control medium } \\
\mathrm{OD} \pm \mathrm{SD}\end{array}$ & $p$ & $\begin{array}{l}\text { High-glucose medium } \\
\mathrm{OD} \pm \mathrm{SD}\end{array}$ & $p$ & $\begin{array}{l}\text { L-glucose osmotic } \\
\text { control medium } \\
\mathrm{OD} \pm \mathrm{SD}\end{array}$ \\
\hline 1 day & 6 & $1.950 \pm 0.257$ & NS & $1.830 \pm 0.094$ & NS & $1.982 \pm 0.314$ \\
\hline 3 days & 20 & $1.902 \pm 0.228$ & $<0.001$ & $1.630 \pm 0.104^{a}$ & $<0.001$ & $2.099 \pm 0.281^{\mathrm{d}}$ \\
\hline 6 days & 18 & $1.924 \pm 0.194$ & $<0.001$ & $1.572 \pm 0.090^{\mathrm{b}}$ & $<0.001$ & $2.047 \pm 0.264$ \\
\hline 10 days & 16 & $1.889 \pm 0.231$ & $<0.001$ & $1.349 \pm 0.085^{\mathrm{c}}$ & $<0.001$ & $1.992 \pm 0.294$ \\
\hline
\end{tabular}

NS vs CD55) exposed to high glucose medium for 3 days. C. Statistically different $(p<0.001)$ from CD55 expression by endothelial cells exposed to high glucose medium for 6 days. D. Statistically different $(p<0.01)$ from CD55 expression by endothelial cells exposed to control medium.
Table 3. Effect of different glucose concentrations on CD59 expression by endothelial cells cultured for 6 days. High glucose concentrations decreased CD59 expression by endothelial cells in a glucose concentration-dependent manner. A. Statistically different $(p<0.001)$ from CD59 expression by cells cultured with $5 \mathrm{mmol} / \mathrm{l}$ D-glucose. B. Statistically different $(p<0.01)$ from CD59 expression by cells cultured with $20 \mathrm{mmol} / \mathrm{l} \mathrm{D}$-glucose

\begin{tabular}{lllll}
\hline $\begin{array}{l}\text { Glucose } \\
\text { concentra- } \\
\text { tion }\end{array}$ & $\begin{array}{l}n \text { of } \\
\text { experi- } \\
\text { ments }\end{array}$ & $\begin{array}{l}\text { D-glucose } \\
\text { OD } \pm \text { SD }\end{array}$ & $p$ & $\begin{array}{l}\text { L-glucose } \\
\text { OD } \pm \text { SD }\end{array}$ \\
\hline $5 \mathrm{mmol} / \mathrm{l}$ & 18 & $1.342 \pm 0.096$ & - & $\mathrm{ND}$ \\
$20 \mathrm{mmol} / 1$ & 10 & $1.180 \pm 0.073^{\mathrm{a}}$ & $<0.02$ & $1.357 \pm 0.103$ \\
$30 \mathrm{mmol} / \mathrm{l}$ & 18 & $1.020 \pm 0.049^{\mathrm{b}}$ & $<0.001$ & $1.281 \pm 0.072$ \\
$40 \mathrm{mmol} / 1$ & 10 & $0.965 \pm 0.027$ & $<0.001$ & $1.421 \pm 0.150$ \\
\hline
\end{tabular}

and Verapamil, $30 \mathrm{mmol} / \mathrm{l}$ D-glucose or $30 \mathrm{mmol} / \mathrm{l} \mathrm{D}$ glucose and Verapamil, and $30 \mathrm{mmol} / \mathrm{l} \mathrm{L}$-glucose or $30 \mathrm{mmol} / \mathrm{l} \mathrm{L}$-glucose plus Verapamil. The results of this study show that Verapamil effected a significant inhibition of the glucose-induced loss of CD59 expression $(196 \pm 41), \quad(p<0.001$ vs $\mathrm{D}$-glucose, $99 \pm$ 25.5), (Fig.4). This effect of Verapamil was not due to a direct cellular mechanism because this agent did not affect the CD59 expression in cells incubated with control medium $(222 \pm 15, n=6)$ or with L-glucose osmotic control medium $(208 \pm 17, n=6)$. Similar results were reproduced for CD55 expression un- der various conditions with or without Verapamil. In particular, CD55 expression was $196 \pm 4(n=6)$ with control medum, $228 \pm 35(n=6)$ with control medium + Verapamil, $43.6 \pm 19 \quad(n=6)$ with D-glucose and $234 \pm 33 \quad(n=6)$ with D-glucose + Verapamil $(p<0.001$ vs D-glucose) .

C5b-9 detection in endothelial cells. C5b-9 was determined in D-glucose and control medium-treated endothelial cells after exposure to AECA negative or AECA positive Ig and fresh human serum. Complement activation was not able to be determined by AECA negative Ig in cells both treated and untreated with D-glucose (not shown). Incubation of AECA positive Ig was followed by a significant increase in C5b-9 formation on endothelial cells treated with $30 \mathrm{mmol} / \mathrm{l} \mathrm{D}$-glucose for 6 days $(0.464 \pm 0.012, n=5)$ when compared with C5b-9 formation on cells treated with $5 \mathrm{mmol} / \mathrm{l}$ D-glucose $(0.249 \pm 0.072, n=5$, $p<0.001$ ) (Fig. 5) or on cells treated with $30 \mathrm{mmol} / \mathrm{l}$ L-glucose $(0.266 \pm 0.054, n=5, p<0.001)$. No difference in lactic dehydrogenase enzyme activity was noted in supernatants of cells either treated or untreated with AECA (not shown). 


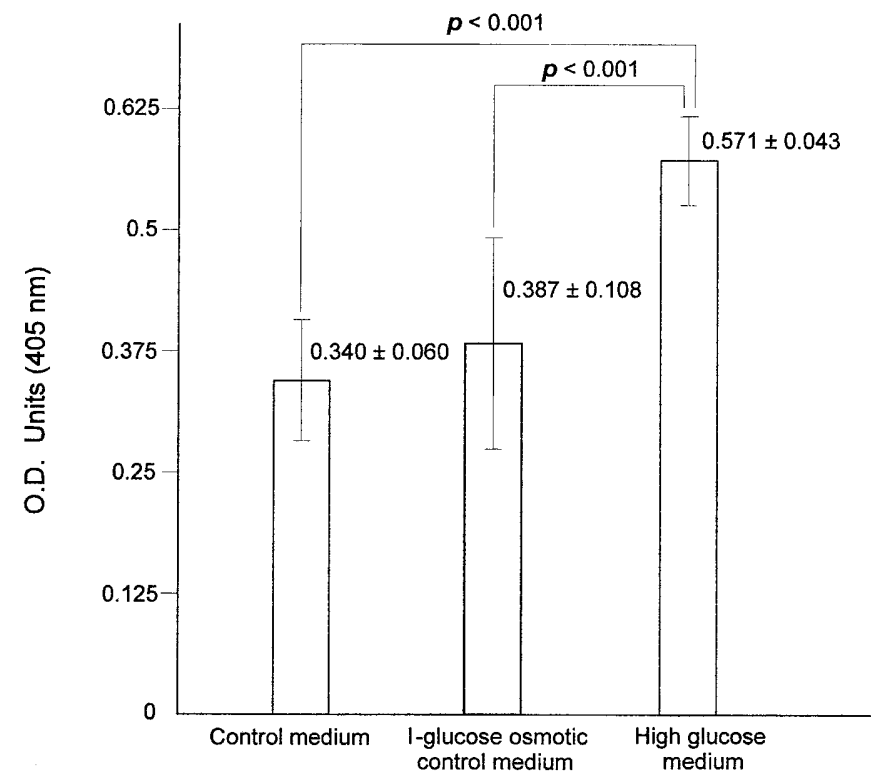

Fig.3. Concentrations of soluble CD59 in supernatants of endothelial cells exposed for 6 days to control medium, L-glucose osmotic control medium and high D-glucose $(30 \mathrm{mmol} / \mathrm{l}) \mathrm{medi}-$ um. Results are expressed as optical density (OD) units \pm standard deviation.

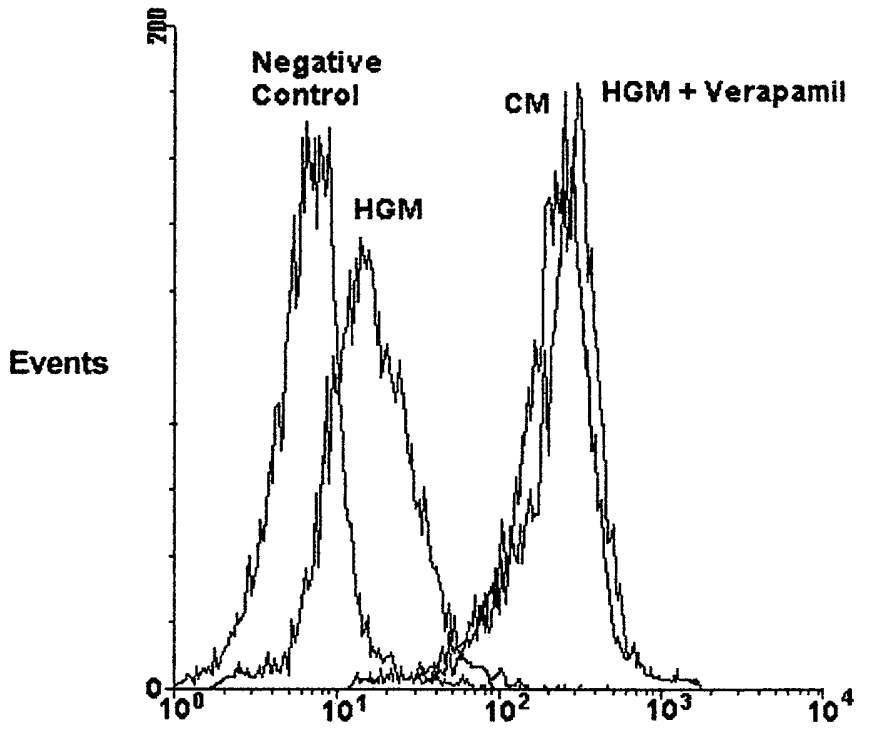

Fluorescence Intensity

Fig. 4. Effect of culturing human endothelial cells with control medium $(\mathrm{CM})$, high $(30 \mathrm{mmol} / \mathrm{l})$ glucose medium (HGM) or high glucose medium plus Verapamil (HGM-V) on CD59 expression. Following 3-day culture, human endothelial cells were then incubated with predetermined optimal binding concentrations of anti-CD59 monoclonal antibody or murine IgG. Surface-bound antibody was detected using fluorescein isothiocyanate-conjugated goat $\mathrm{F}(\mathrm{ab}) 2$ anti-mouse $\mathrm{Ig}$, and fluorescence intensity was measured by flow cytometry. Data shown are from a representative experiment, with fluorescence intensity along the $\mathrm{x}$ axis and number of events along the y axis. Similar results were observed in six repeat experiments.

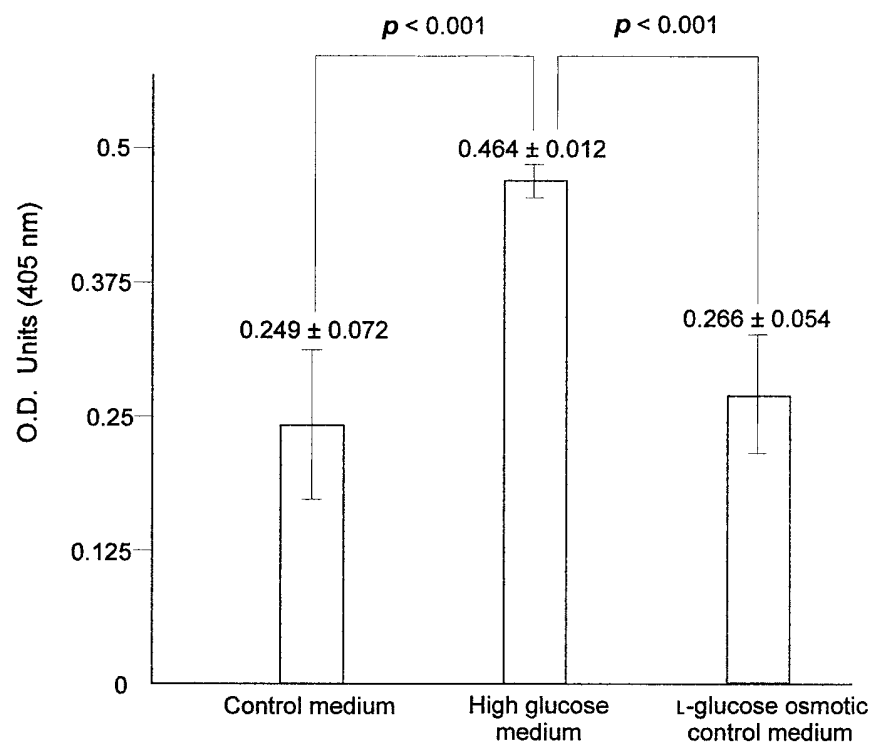

Fig. 5. C5b-9 (MAC) detection on endothelial cells exposed for 6 days to control medium, high D-glucose medium or L-glucose osmotic control medium after incubation with AECA positive IgG and fresh human serum (as autologous complement donor). Results are expressed as optical density (OD) units.

\section{Discussion}

The complement system is constantly activated in vivo and could potentially induce damage to exposed autologous cells including endothelial cells. Recent functional, structural and genetic studies have shown the existence of several molecules (mRCA, membrane regulators of complement activation) embedded in the cell membranes that inhibit complement activation on the cell surface and thereby protect them from autologous complement [9]. Two membrane proteins, decay accelerating factor (DAF, CD55) and membrane cofactor protein (MCP, CD46), restrict complement activation on self cell at the C3/C5 convertase formation stage [13]. The formation of membrane attack complex (MAC) on self cells is strictly regulated by a recently described 18,000-20,000 $\mathrm{M}_{\mathrm{r}}$ glycoprotein (membrane inhibitor of reactive lysis, MIRL, CD59) [14]. In particular, CD59 was identified as a wide tissue-distributed glycoprotein that inhibits the transmembrane channelforming function of homologous $\mathrm{C} 8$ and $\mathrm{C} 9$ at the final stage of MAC formation [15]. Both CD55 and CD59 belong to a family of membrane proteins that are attached to the outer leaflet of the cell membranes through a GPI (glycosyl-phosphatidylinositol) moiety [16]. On the other hand, CD46 is a single chain protein that possesses a hydrophobic transmembrane-spanning domain and a basic amino acid region typical of the cytoplasmic anchor [17]. Antigens CD55 and CD59 expressed on the surface of endothelial cells can be removed by PI-PLC treatment 
[18]. This is in agreement with the finding that CD55 and CD59 expression is absent from the surface of affected erythrocytes in patients suffering from paroxysmal nocturnal haemoglobinuria, where glycolipid anchors are not expressed on their surface [19].

Hyperglycaemia is one of the major factos causing accelerated vascular and renal disease in both Type 1 (insulin-dependent) and Type 2 (non-insulin-dependent) diabetes mellitus and can mediate its adverse effect through multiple pathways, one of these mechanisms being the activation of protein kinase $\mathrm{C}$ (PKC) by inducing increases in diglycerol levels. The activation of PKC regulates various vascular functions by modulating also phospholipase activity [20]. A key role of glucose in inducing anchor processing due to endogenous PI-PLC has been also documented representing this effect as a mechanism in the regulation of cell wall expression of GPI-anchored proteins [21].

In this paper we describe a novel action of increased $(30 \mathrm{mmol} / \mathrm{l})$ glucose concentration in endothelial cells which could profoundly influence endothelial cell function, notably the lack of expression of the glycolipid-anchored CD55 and CD59.

We did not investigate the mechanism by which CD55 and CD59 were lost during exposure to high glucose concentrations. The inhibitory effect of high glucose concentrations could theoretically be attributed to osmotic changes due to a hypertonic glucose solution. The failure of $\mathrm{L}$-glucose to duplicate the effect of high glucose concentrations in our study points, however, to a biochemical rather than a physical effect of glucose. Indeed, an early increase of all mRCA molecule expression was observed in cells treated with L-glucose. This phenomenon was observed in ELISA but not in flow cytometric studies indicating that different cell numbers/confluence in the monolayer might be responsible for this effect. The possibility that osmotic changes might be considered a potential stimulus for increasing mRCA molecules could be raised and specifically addressed with new studies. The decrease in CD55 and CD59 expression was seen to be correlated with the duration of exposure to D-glucose in ELISA studies but reaching maximum after 3 days when studies were done by flow cytometry indicating that variables in methods might influence the results. These data do not seem to be in contrast, however, with the hypothesis of a role of D-glucose in the loss of mRCA molecules.

In Psoriasis, activated membrane PLC could be responsible for the splitting of the GPI anchor of the GPI proteins $[22,23]$. The observed sensitivity of endothelial cell CD59 [18] and of myocardial CD59 [24] to phospholipase $\mathrm{C}$ and the effect of glucose on cytosolic calcium levels [25] and on calcium-dependent phospholipase $C$ activation $[26,27]$ suggest that PLC could be involved in the lack of CD59 and CD55 endothelial cell expression after glucose exposure.
Much is known about PLC specific for inositol phospholipids. The observed effect of exogenous PLC on hydrolysing inositol lipids located on the outer leaflet of plasma membrane and CD59 release was previously reported [18, 24]. With the exception of a study involving fungus [21] there is, according to our knowledge, no information on the role of glucose in inducing anchor processing in humans due to endogenous PI-PLC. Little data is available on the presence of a less common cell surface-exposed PI-PLC [28, 29].

The present work was not specifically addressed to investigate the intrinsic mechanism by which high glucose could operate in determining PI-PLC activation and CD55/CD59 splitting and further studies should be performed to identify changes in PLC and PKC activity. The notion, however, that high glucose concentrations might activate L-type calcium channels by $\mathrm{G}$ protein involvement that in turn could stimulate the phospholipase $\mathrm{C}$ pathway $[25,30,31]$, together with studies in diabetic patients and in animals with experimental diabetes that show elevation in basal levels of cytosolic calcium of many cells [32] support our hypothesis that an increase in cytosolic calcium with subsequent cytoplasmatic PLC activation might play a part in the loss of CD55 and CD59. The effect of high glucose concentrations inducing processing of a glycosyl-phosphatidylinositol-anchored membrane ectoprotein in Saccaromices [21] further support this hypothesis. Other results in our study are also in agreement with this hypothesis: 1) the expression of the transmembrane protein CD46 was almost unaffected when endothelial cells were incubated with a medium containing a high glucose concentration; 2) the loss of CD59 and CD55 antigen after glucose incubation was completely reversed by co-incubation of cells with Verapamil, an agent that is known to block L-type calcium channels and PLC activity [25-27]; 3) increased concentrations of the soluble form of CD59 were found in the supernatants of endothelial cells treated with high glucose concentration medium when compared with concentrations observed in supernatants of cells treated with control medium or control medium supplemented with L-glucose.

In a previous work we found increased concentrations of the soluble noncytolytic form of C5b-9 in the plasma of diabetic patients were associated with a marker of endothelial cell dysfunction (von Willebrand Factor) and increased concentrations of urinary microalbuminuria [8]. In this study we also investigated the effect of high glucose concentrations on C5b-9 (MAC) formation on endothelial cells. An increased susceptibility of cells to the deposition of MAC was observed when glucose-treated endothelial cells were exposed to antiendothelial cell antibodies and complement.

In spite of the important role of mRCA molecules in protection from autologous complement, a limited 
number of studies have been carried out in disease states. Because of their protective function, lack of expression of mRCA molecules is likely to cause tissue damage and disease. The MAC formation, however, was not followed in our experiments by Lysis, assessed by the measurement of lactic dehydrogenase enzyme activity. Indeed, several non lethal effects of MAC have been described on endothelial cells that include the induction of a variety of biologically active molecules as metabolites of arachidonic acid, reactive oxygen metabolites, interleukines and enzymes [33].

Many factors contribute to the development of the vascular complications targeting endothelial cells. In particular, in the last years, immunological factors such as circulating immune complexes [34, 35], and antibodies with antiproteoglycan [36] and antiendothelial cell reactivity [4] have been detected in diabetes and considered to play an important part in complement activation and in the pathogenesis or progression of diabetic angiopathy. Moreover, although this was not the object of the present study, it is interesting to note the observation that the distinguishing feature that decides whether cells or certain particles will or will not activate complement could be the amount of sialic acid or sulphated mucopolysaccharides present on the surfaces $[37,38]$. Sialic acid and mucopolysaccharides are known to be significantly reduced in the basement membranes of human diabetes [39], thus low concentrations might facilitate a membrane complement activation in diabetes in the presence of discrete or undetectable immune abnormalities.

In conclusion, the role of high glucose concentrations in determining a loss of GPI-anchored mRCA molecules is reported in our study. We speculate on a possible cooperation between metabolic and immunological factors, causing glucose-mediated loss of endothelial mRCA which could facilitate the activation of the complement pathway and an endothelial cell dysfunction.

Acknowledgements. Dr. A. Accardo-Palumbo is a post doctoral PhD student and recipient of a fellowship from the Ministero della Università e della Ricerca Scientifica of Italy. This study was supported by grants from Ministero della Università e della Ricerca Scientifica e Tecnologica of Italy and from Assessorato ai Beni Culturali della regione Sicilia. The authors wish to thank Dr. U. Piovana for measurement of lactic dehydrogenase enzyme activity and Mr. S. Taormina for preparing illustrative materials.

\section{References}

1. Porta M, La Selva M, Molinatti P, Molinatti CM (1987) Endothelial cell function in diabetic microangiopathy. Diabetologia 30: 601-609

2. Kim JA, Berliner JA, Natarajan RD, Nadler JL (1994) Evidence that glucose increases monocyte biding to human aortic endothelial cells. Diabetes 43: 1103-1107
3. Lorenzi M (1992) Glucose toxicity in the vascular complications of diabetes: the cellular perspectives. Diabetes Metab Rev 8: 85-103

4. Triolo G, Triolo G, Accardo-Palumbo A et al. (1998) IgG antiendothelial cell antibodies (AECA) in type 1 diabetes mellitus: induction of adhesion molecule expression in cultured endothelial cells. Clin Exp Immunol 111: 491-496

5. Westberg NG, Michael AF (1972) Immunopathology of diabetic glomerulosclerosis. Diabetes 21: 163-174

6. Mauer SM, Steffes MW, Michael AF, Brown SM (1976) Studies of diabetic nephropathy in animals and in man. Diabetes 25: 850-857

7. Falk RJ, Podack E, Dalmasso AP, Jennette JC (1987) Localization of $S$ protein and its relationship with the membrane attack complex of complement in renal tissue. Am J Pathol 127: 182-190

8. Triolo G, Giardina E, Casiglia D, Scarantino G, Bompiani GD (1991) Detection of the terminal fluid-phase complement complex, sC5b-9, in the plasma of patients with insulin-dependent (type 1) diabetes mellitus. Relation to increased urinary albumin excretion and plasma von Willebrand factor. Clin Exp Immunol 84: 53-58

9. Asghar SS (1995) Membrane regulators of complement activation and their aberrant expression in disease. Lab Invest 72: 254-271

10. Lubin DM, Coyne KE (1991) Phospholipid-anchored and transmembrane forms of either decay accelerated factor or membrane cofactor protein show equal efficiency in protection from complement-mediated cell damage. J Exp Med 174: 35-44

11. Nalsh LA, Tone M, Thiru S, Waldmann H (1992) CD59 artigen: A multifunctional molecule. Tissue Antigens 40: 213-220

12. Jaffe EA, Nachman RL, Becker GE, Minick CR (1973) Culture of human endothelial cells derived from umbilical veins. J Clin Invest 52: 2745-2756

13. Hourcada D, Holers VM, Atkinson JP (1989) The regulators of complement activation (RCA) gene cluster. Adv Immunol 45: 381-416

14. Okada N, Harada R, Fujita T, Okada H (1989) A novel membrane glycoprotein capable of inhibiting membrane attack by homologous complement. Int Immunol 1 : 205-208

15. Rollins SA, Zhao JJ, Ninomja H, Sims PJ (1991) Inhibition of homologous complement by CD59 is mediated by a species selective recognition conferred through binding to $\mathrm{C} 8$ within C5b-8 or C9 within C5b-9. J Immunol 146: 2345-2351

16. Low MG, Saltiel AR (1988) Structural and functional roles of glycosyl-phosphatidylinositol in membranes. Science 239: 268-275

17. Post TW, Lisrewski MK, Adams EM, Tedja I, Miller EA, Atkinson JP (1991) Membrane cofactor protein of the complement system: alternative splicing of serine/threonine/proline rich exons and cytoplasmic tails produces multiple isoforms that correlate with protein phenotype. J Exp Med 174: 93-102

18. Brooimans RA, Van Wieringen PA, Van Es LA, Daha MR (1992) Relative roles of decay-accelerating factor, membrane cofactor protein and CD59 in the protection of human endothelial cells against complement mediated lysis. Eur J Immunol 22: 3135-3140

19. Womtovian R, Prince GM, Medof ME (1993) The molecular basis of paroxysmal nocturnal hemoglobinuria. Transfusion 33: 852-873

20. Ishii H, Koya D, King JL (1998) Protein kinase C activation and its role in the development of vascular complications in diabetes mellitus. J Mol Med 76: 21-31 
21. Müller G, Gross E, Wied S, Bandlow W (1996) Glucose-induced sequential processing of a glycosyl-phosphatidylinositol-anchored ectoprotein in Sacharomyces cerevisiae. Mol Cell Biol 16: 442-456

22. Venneker GT, Das PK, Meinardi MM et al. (1994) Glycosylphosphatidylinositol (GI) anchored membrane proteins are constitutively down regulated in psoriatic skin. J Pathol 172: $189-197$

23. Fisher GJ, Talwar HS, Tavakkol A et al. (1990) Phosphoinositide-mediated signal transduction in normal and psoriatic epidermis. J Invest Dermatol 95: 515-517

24. Väkevä A, Laurila P, Meri S (1992) Loss of expression of protectin (CD59) is associated with complement membrane attack complex deposition in myocardial infarction. Lab Invest 67: 608-616

25. Demerdash TM, Seyrek N, Smogorreyski M, Marcinkowski W, Nasser-Moadelli S, Massry SG (1996) Pathways through which glucose induces a rise in $\left[\mathrm{Ca}^{2+}\right] \mathrm{i}$ of polymorphonuclear leukocytes of rats. Kidney Int 50: 2032-2040

26. Malm D, Giaever A, Vonen B, Florholmen J (1993) Cholecystokin and somatostatin modulate the glucose-induced insulin secretion by different mechanisms in pancreatic islets. A study on phospholipase $\mathrm{C}$ activity and calcium requirement. Scand J Clin Lab Invest 53: 671-676

27. Mathias PC, Best L, Malaisse WJ (1985) Stimulation by glucose and carbamylcholine of phospholipase $\mathrm{C}$ in pancreatic islet. Cell Biochem Funct 3: 173-177

28. Birrell GB, Hedberg KK, Barklis E, Griffith OH (1997) Partial isolation from intact cells of a cell surface-exposed lysophosphatidylinositol-phospholipase C. J Cell Biochem 65: 550-564

29. Miscia S, DiBaldassarre A, Cataldi A, Rana RA, DiValerio V, Sabatino G (1998) Novel evidence of expression and ac- tivity of ecto-phospholipase C gamma 1 in human T lymphocytes. Blood 91: 3833-3840

30. Gilman AG (1987) G proteins: Transducers of receptorgenerated signals. Annu Rev Biochem 56: 615-669

31. Hruska KA, Moskowitz D, Eshrit P, Civitelli R, Westbrook S, Huskey M (1987) Stimulation of inositol triphosphate and diaglycerol production in renal tubular cells by parathyroid hormone. J Clin Invest 79: 230-239

32. Levy J, Gavin JR 3rd, Sowers JR (1994) Diabetes mellitus: A disease of abnormal cellular calcium metabolism? Am J Med 96: 260-273

33. Morgan BP (1989) Mechanisms ot tissue damage by the membrane attack complex of complement. Complement Inflamm 6: 104-111

34. Triolo G, Davi G, Giardina E et al. (1984) Circulating immune complexes and platelet thromboxane synthesis in patients with insulin-dependent type 1 diabetes mellitus. Diabetes 33: 728-731

35. Triolo G, Giardina E, Rinaldi A, Bompiani GD (1984) IgA- and insulin-containing (C3-fixing) circulating immune complexes in diabetes mellitus. Clin Immunol Immunopathol 130: 169-177

36. Triolo G, Giardina E, Scarantino G et al. (1989) Cross-reactivity of anti-ssDNA antibodies with heparan sulfate in patients with type 1 diabetes mellitus. Diabetes 38: 718-722

37. Reid KB, Porter RR (1981) The proteolytic activation systems of complement. Annu Rev Biochem 50: 433-464

38. Michalek MT, Bremer EG, Mold C (1988) Effect of gangliosides on activation of the alternative pathway of human complement. J Immunol 140: 1581-1587

39. Parthasarathy N, Spiro RG (1982) Effect of diabetes on glycosaminoglycan component of the human glomerular basement membrane. Diabetes 31: 738-741 